\title{
Does where you plant trees make a difference in hydrologic response?
}

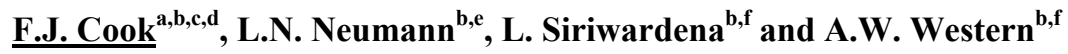 \\ ${ }^{a}$ Freeman J Cook and Associates Pty Ltd, ${ }^{b}$ eWater Cooperative Research Centre, ${ }^{c}$ CSIRO Land and Water \\ ,Dutton Park, Queensland, ${ }^{d}$ The University of Queensland, ${ }^{e}$ CSIRO Land and Water, Highett, Victoria, ${ }^{f}$ The \\ University of Melbourne, Melbourne, Victoria \\ Email:freeman.j.cook@gmail.com
}

\begin{abstract}
Riparian zones are considered to be a good way of reducing water flow and sediment losses to streams, but is planting trees further away from the stream bank just as effective? Here we have used a combination of analytical models and numerical models to estimate the likely effects of the positioning of trees in a catchment on the hydrologic response. An analytical model of a planar slope was used extended in a piecewise manner to determine the effect of varying roughness of a section of the slope on runoff depth, velocity and quantity. This was compared to a numerical solution of the full flow equation on a slope. Results show that the analytical solution predicts a larger runoff depth than the numerical solution, which is to be expected as it ignores some of the terms in the full solution. The numerical model shows the same abrupt transient in head (height of water on soil surface) at a change in roughness assumed in the analytical model.
\end{abstract}

A uniform planar slope of length of $100 \mathrm{~m}$ was split into 4 equal quarters and the effect of slope, runoff rate and roughness on the discharge rate at each quarter and at the bottom of the slope was investigated with the analytical model. This showed that the discharge rate would change in quarter with different roughness but relax back to the original discharge rate in the next quarter of the slope, when the changed occurred in the upper 3 quarters of the slope. Only when the roughness change occurred in the last quarter of the slope was the discharge rate affected at the bottom of the slope. Slope angle was found to have the least effect on changing discharge rate at the bottom of the slope. The numerical solution though, could not produce a stable solution when the length of the slope length, runoff rate, roughness and slope angle were large, while the analytical solution was able to produce results in all cases considered.

Neither the analytical or numerical solutions of flow down the sloping surface included the effect of prior soil conditions on the amount of runoff generated. In order to investigate soil and climate effects on runoff the problem was also solved using the THALES catchment model. Results with the catchment model THALES generally supported the analytical model but also allow the climate and soils (infiltration and evapotranspiration) when the vegetation was changed to be assessed. Three contrasting sites were chosen; Melbourne, Brisbane and Perth, along with three soil materials (clay(C), clay loam (CL) and sandy loam (SL)). The soil materials were used to created soil profiles with four $0.3 \mathrm{~m}$ layers (total depth $1.2 \mathrm{~m}$ ); soil\#1 SL for all four layers; soil\#2 SL for top layer and CL for lower 3 layers; and soil\#3 C for all 4 layers. Two slopes; A1 $-10^{\circ}$ and $\mathrm{A} 2-30^{\circ}$ were used, and combined with three soils and 3 sites resulted in 18 scenarios. The results showed that the planting of trees at different positions of the slope had an effect for sandy loam soils and moderate slopes in a winter dominated rainfall climate like Melbourne. However, for a summer dominated rainfall like Brisbane the position of the trees did not significantly affect the amount of runoff generated. The position of where the trees were planted was only shown to have a significant effect in Melbourne, where the further down slope the trees were planted the more they intercepted subsurface flow and evapotranspired this, reducing runoff. Again slope was shown to have the smallest effect on runoff except for two of the scenarios investigated. Given the time requirement to run the analytical solution offers a quick and reasonably robust way to determine the effects of changes in soil, typographic, vegetation and runoff rate on runoff generated at the bottom of a planar slope.

Keywords: $\quad$ Runoff, trees, water balance 


\section{INTRODUCTION}

The runoff and flow of water on sloping surfaces is a topic that has been much studied in hydrology (Moore and Foster, 1990), as well as the effect of tree planting and positioning on runoff and water balance of the soil (Ellis, et al., 2006; Ticehurst, et al., 2007; Zhao, et al., 2010). However, these studies are either for specific cases (Ellis, et al., 2006; Ticehurst, et al., 2007) or at the catchment scale (Zhao, et al., 2010). Here we will use a combination of analytical and numerical modelling to investigate the consequences of the positioning of a block of trees on a planar slope in terms of the runoff generated and flow of water down the sloping surface. We will use a planar slope of $100 \mathrm{~m}$ in length and divide this into quarters. The analysis is based on a change of roughness for one quarter of the hillslope and its influence on the flow depth and runoff, as shown schematically in Figure 1. Runoff can be generated either by saturation excess or infiltration excess. Once generated it will start to flow down slope due to the gravitational body force on the water and slowed by frictional forces. This flow can be described by (Moore and Foster, 1990):

$$
\begin{aligned}
& w \frac{\partial h}{\partial t}+\frac{\partial Q}{\partial x}=I \\
& Q=Q_{n}\left\{1-\frac{1}{S_{0}}\left(\frac{d h}{d x}+\frac{u}{g} \frac{d u}{d x}+\frac{1}{g} \frac{d u}{d t}+\frac{u I}{g h}\right)\right\}^{1 / 2}
\end{aligned}
$$

where $Q$ is the discharge $(Q=u A)\left[\mathrm{L}^{3} \mathrm{~T}^{-1}\right], u$ is the depth averaged velocity [ $\left.\mathrm{L} \mathrm{T}^{-1}\right]$ in direction $x[\mathrm{~L}], A$ is the cross-sectional area normal to the flow $\left[\mathrm{L}^{2}\right], h$ is the mean depth (head) on the soil surface [L], $S_{0}$ is the slope $\left[\mathrm{L} \mathrm{L}^{-1}\right], g$ is the gravitational acceleration $\left[\mathrm{L} \mathrm{T}^{-2}\right], t$ is time $[\mathrm{T}], w$ is the flow width at the water surface $[\mathrm{L}]$ and $I$ is the lateral inflow rate per unit width $\left[\mathrm{L}^{2} \mathrm{~T}^{-1}\right]$. We will solve eqn (1) numerically for a planar slope with a different roughness on $1 / 4$ section of the slope. The change in roughness is abrupt at both interfaces of the quarter with the roughness change and uniform roughness is applied on the other $3 / 4$ of the slope.

Henderson and Wooding (1964) used a simplification of eqn (1) (the kinematic wave equation which ignores the terms multiplied by $1 / S_{0}$ in eqn (1)) to derive an equation for flow or discharge rate:

$$
q=\alpha h^{m}
$$

where, $q=Q / w\left[\mathrm{~L} \mathrm{~T}^{-1}\right]$, for laminar flow $\alpha=g S_{0} / 3 \eta$ and $m=3, \eta$ is the kinematic viscosity, and for turbulent flow $\alpha=C_{1} S_{0}^{1 / 2}$ and $m=3 / 2$, where $C_{1}$ is the Chezy coefficient.

\subsection{Piecewise Analytical Solution for Flow on a Planar Slope}

Wooding (1965) used eqn (2) to derive the hydrograph for flow on a planar slope with constant rainfall and here we will extend that to a piecewise solution where the roughness of the slope changes abruptly from block to block (Figure 1) in the hillslope. For the first block in the slope sequence the equations for flow are just those from Wooding (1965) with the height of the water above the soil surface (ignoring the first part where the head changes with distance down slope) as given by

$$
\begin{array}{ll}
h=v_{0} t, & 0<t \leq t_{s} \\
h_{s}=v_{0} t_{s}=\left(v_{0} X / \alpha_{1}\right)^{1 / m}=\left(q_{s} / \alpha_{1}\right)^{1 / m}, & t>t_{s}
\end{array}
$$

where $X=L / 4, L$ is the total length of the hillslope, $v_{0}$ is the steady state runoff rate $\left[\mathrm{L} \mathrm{T}^{-1}\right], t_{s}$ is the time when steady-state conditions occur [T] and $h_{s}$ is the steady-state head [L]. We assume that flow is continuous across the boundary between the blocks $i$ and $i+1$ (ie ) $q_{i}=q_{i+1}$. From eqn (2) this will result in $h_{i}\left(x_{i, i+1}\right)=h_{i+1}\left(x_{i, i+1}\right)=\left(\alpha_{i} / \alpha_{i+1}\right)^{1 / m}$ which implies that an abrupt change in head will occur. The flux at the end of the next segment is given by:

$$
\begin{aligned}
q_{i} & =\alpha_{i} t^{m} v_{0}^{m}, & & t \leq\left[X . i /\left(\alpha_{i} v_{0}^{m-1}\right)\right]=t_{s i} \\
& =v_{0} X . i, & & t>t_{s i}
\end{aligned}
$$

The runoff at the end of each block can be determined by integration of eqn (3) or (4):

$$
\begin{aligned}
& \begin{aligned}
Q(x, t) & =\int_{0}^{t} q(x, \beta) d \beta=\int_{0}^{t} \alpha(x)\left[v_{0} \beta\right]^{m} d \beta=\alpha(x) v_{0}^{m} t^{m+1} /(m+1), \quad t \leq t_{s}(x), x=X . i \\
= & \int_{0}^{t_{s}} \alpha(x)\left(v_{0} \beta\right)^{m} d \beta+\int_{t_{s}}^{t} v_{0} x d \beta=\alpha(x) v_{0}^{m} t_{s}^{m+1} /(m+1)+v_{0} x\left(t-t_{s}\right), \quad t>t_{s}
\end{aligned} \\
& R o(x, t)=Q(x, t) / x
\end{aligned}
$$




\subsection{Numerical solution of Kinematic Wave Equation}

Eqn (1) can be written so that it has similarities to Richards equation for water flow in porous media:

$$
\begin{aligned}
& \frac{\partial h}{\partial t}=-\frac{\partial q}{\partial x}+v_{0} \\
& q(x, t)=-K(h)\left(\frac{\partial h}{\partial x}-S_{0}\right)
\end{aligned}
$$

where the hydraulic conductivity like term $K(h)=\sqrt{8 g h^{3} / f}$ and $f$ is the Darcy-Weisbach resistance. Eqn (6) can be solved numerically using one of the many solvers available for the Richards equation.

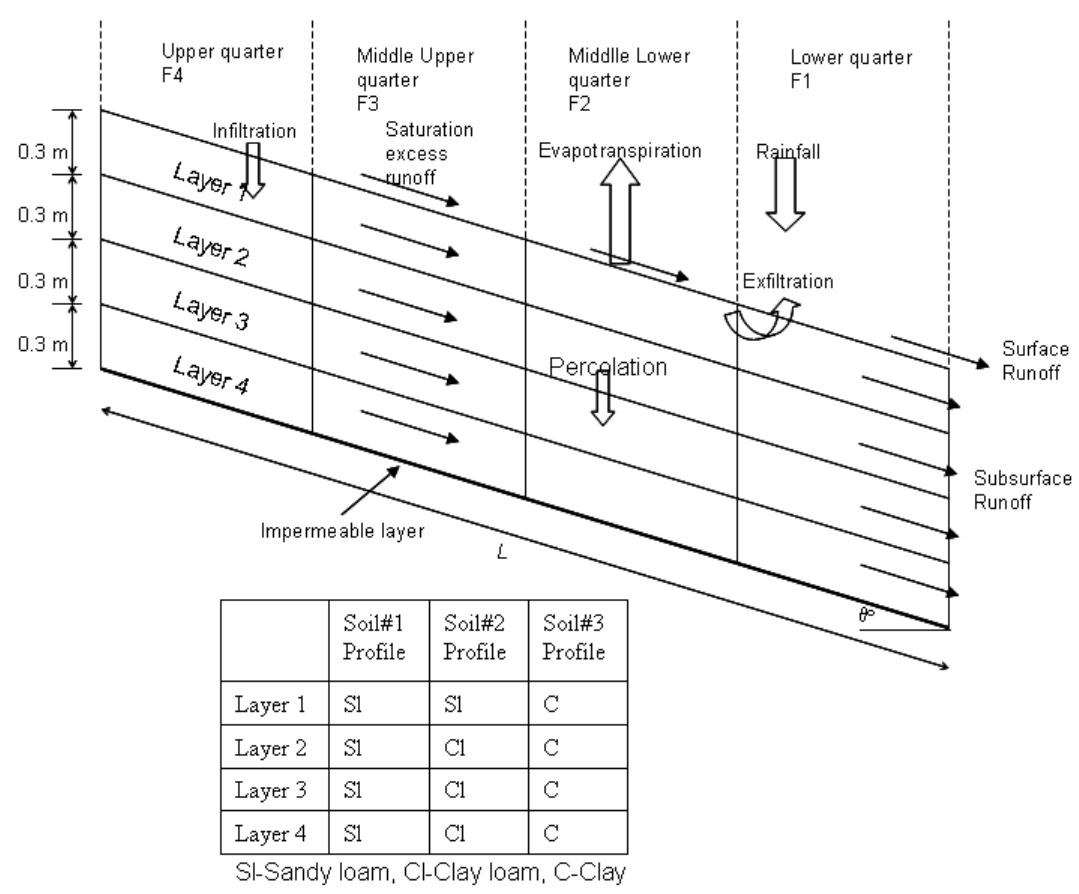

Figure 1. Schematic of slope sequence at an angle of $\theta$ to the horizontal, a slope length of $L$ divided into quarters $(L / 4)$. One of the four quarters can have a different roughness. In the THALES modeling the subsurface runoff was also included and the soil profile was varied over the whole slope.

\subsection{THALES Catchment Model}

Thales is a distributed hydrological model designed for application to small catchments, based on the Thales framework (Grayson et al., 1995; Western and Grayson, 2000) as used by Neumann et al. (2007; 2010). The model represents the catchment using a grid-based element network surface and subsurface flow routed using the D $\infty$ method (Tarboton, 1997) for hillslope elements. The soil can be represented by as many layers as desired, with lateral movement of water possible in all layers and the surface.

Soil moisture in each layer in each element is modelled with a water balance, using rainfall, surface and subsurface flow from upslope as inputs. Outputs of water are evapotranspiration, surface and subsurface flow downslope, and deep seepage. Surface flow is routed using kinematic routing and is generated either when an element is saturated or when the infiltration capacity is exceeded. The model assumes Brooks and Corey's (Brooks and Corey, 1964) relationship for soil water retention and hydraulic conductivity characteristics.

A single store is used to represent the soil moisture in each soil layer and it varies between the permanent wilting point, $\theta_{p w p}$, and saturation (i.e. porosity), $\theta_{\text {sat }}$. Subsurface lateral flow occurs when saturated conditions occur in the layer (based on Brookes-Corey soil water retention curve and a hydrostatic mositure profile assumption) and outflows are calculated using Darcy's Law and the topographic slope. Surface outflow rates are calculated using Manning's formula assuming sheet flow for hillslope elements. 


\section{METHODS}

The analytical solutions were solved for a range of slopes, runoff rates and Darcy-Weisbach resistances (Table 2). The Chezy coefficient was calculated using the Darcy-Weisbach resistance factor and the relationship $C_{1}=\sqrt{8 g / f}$. Wooding (1965) suggests that for most catchments flow will be approximately turbulent and a value of $m=2$ as used by Horton $(1936,1940)$ is appropriate. The numerical solution of eqn (6) was solved using MatLab (The MathWorks, 2004) and the methods of lines and the ODE solver ODE15s for stiff problems (Hairer and Wanner, 1991). The same values were used for the numerical calculations.

THALES calculations were made for three sites viz Melbourne, Brisbane and Perth to evaluate a range of climate variables. The soil was split into 4 layers of $0.3 \mathrm{~m}$ thickness and each layer was allowed to vary in soil properties (see Figure 1). The bottom layer was considered to be impervious with no deep drainage. Each section of the $100 \mathrm{~m}$ hillslope section of $2.5 \mathrm{~m}$ by $25 \mathrm{~m}$ was represented by 120 cells, 3 cells wide (into the page in Figure 1) and 40 cells long. Two values of the hillslope angle $(\theta)$ were used $10^{\circ}$ (A1) and $30^{\circ}$ (A2). The soil properties are taken from Carsel and Parish (1988) for the textural classes shown in Figure 1. The initial soil moisture was assumed to be $0.10,0.15,0.20$ and 0.25 for layers 1 to 4 respectively. The modelling period was from 1961 to 1990 and 6 minute climate data was used in the simulations. The mean annual rainfall and potential evapotranspiration (PET) for the three sites are; Melbourne Regional Office (site no. 86071, rainfall $628 \mathrm{~mm}$, PET $1110 \mathrm{~mm}$ ), Brisbane Aero (site no. 40223, rainfall $1222 \mathrm{~mm}$, PET $1581 \mathrm{~mm}$ ) and Perth Airport (site no. 09021, rainfall $755 \mathrm{~mm}$, PET $1475 \mathrm{~mm}$ ).

Different vegetation scenarios for the hillslope sections were considered. Two scenarios were used as the standard scenarios for pasture and forest: pasture without canopy capacity over the whole slope (PAST) and forest with canopy capacity over the whole slope (FRST). The remaining scenarios considered one quarter of the hillslope being forest and the other 3 quarters being pasture, with forest on the upper quarter of the slope (F4) and pasture the rest and then for forest of second, third and fourth quarters (F3, F2 and F1 respectively). The vegetation properties and soil properties are given in Table 1.

Table 1. Vegetation and soil properties for THALES simulation.

\begin{tabular}{|c|c|c|c|c|c|c|}
\hline Vegetation Property & Pasture & Forest & Soil Property & Sandy Loam (SL) & Clay Loam (CL) & Clay (C) \\
\hline Fractional cover & 1 & 1 & Wilting point $\theta_{p w p}$ & 0.08 & 0.14 & 0.25 \\
\hline Root depth (m) & 0.6 & 1.2 & Porosity $\theta_{\text {sat }}$ & 0.412 & 0.39 & 0.39 \\
\hline ET factor $(0-0.3 \mathrm{~m})$ & 1 & 1 & $\begin{array}{l}\text { Ksat-horizontal } \\
(\mathrm{mm} / \mathrm{hr})\end{array}$ & 25.9 & 2.3 & 0.6 \\
\hline \multirow[t]{5}{*}{ ET factor $(0.6-1.2 \mathrm{~m})$} & 0.5 & 0.5 & Air entry $(\mathrm{cm})$ & 14.7 & 25.9 & 37.3 \\
\hline & & & Alpha $(\alpha)\left(\mathrm{cm}^{-1}\right)$ & 0.0680 & 0.0386 & 0.0268 \\
\hline & & & $n$ & 0.322 & 0.194 & 0.131 \\
\hline & & & $l$ & 2.0 & 2.0 & 2.0 \\
\hline & & & $\begin{array}{l}\text { Brooks-B } \\
\text { coefficient }\end{array}$ & 3.6 & 5.7 & 8.1 \\
\hline
\end{tabular}

\section{RESULTS AND DISCUSSION}

The numerical solution from eqn (6) gave slightly lower values of the head than the analytical solution of Wooding (1965). Both solutions give a sharp rise in head on the change to rougher surface at $x=25 \mathrm{~m}$, the analytical model predicts a change in head of $0.7 \mathrm{~mm}$, while the numerical model predicts a change of $0.5 \mathrm{~mm}$. Similarly a sharp decline in head occurs at $x=50 \mathrm{~m}$ with the predicted changes being 1.02 and $0.98 \mathrm{~mm}$ for the analytical and numerical models respectively. Other examples gave similar results, which suggests the analytical model can predict well the relative change in head when roughness changes.

The analytical model was used to firstly calculate the effect of changes in $f, v_{0}$ and $S_{0}$ on $h$ for slopes with uniform cover (Figure 3 ).

Table 2. Surface property values used in runoff calculations.

\begin{tabular}{|c|c|c|c|}
\hline \multirow{2}{*}{ Value } & \multicolumn{3}{|c|}{ Property } \\
\cline { 2 - 4 } & Slope & $v_{0}\left(\mathrm{~mm} \mathrm{day}^{-1}\right)$ & $f$ \\
\hline Low & 0.01 & 10 & 20 \\
\hline Medium & 0.1 & 50 & 40 \\
\hline High & 0.50 & 100 & 60 \\
\hline
\end{tabular}

The values of resistance $f$ represent low (low pasture), medium (shrubs and tall grasses) and high (trees with dense understorey). 
The medium values in Table 2 were used as the standard. The results show that roughness, $f$, had the least effect on changing the head on the soil surface compared to slope, $S_{0}$, and runoff rate, $v_{0}$ (Figure 3). However, when the last quarters of the slope had the value of $f$ changed, the effect on the runoff from the end of the slope was least affected by slope.

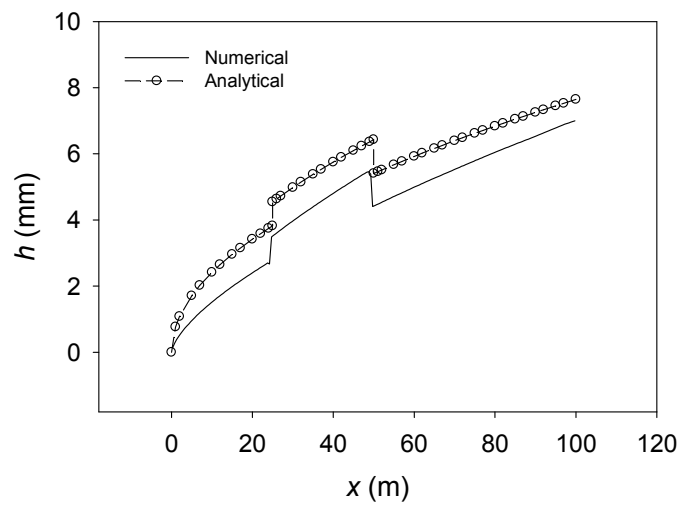

Figure 2. Comparison of $h$ from numerical solution of eqn (6) and analytical solution from eqn (2). $L=100 \mathrm{~m}, v_{0}=0.01 \mathrm{~m} \mathrm{day}^{-1}, S_{0}=0.01$ and $f=20$ (low pasture) for quarters $1,3 \& 4$ and $f=40$ for quarter 2 .

Here we will only present results of the variation in runoff when the value of $f$ was changed from medium to low or medium to high values, as this covers the entire range of behaviour. The change in $f$ from medium to a low value increased the amount of runoff from the end of the section and the opposite effect when $f$ changed to the high value ( $x=50 \mathrm{~m}$, Figure 2$)$.

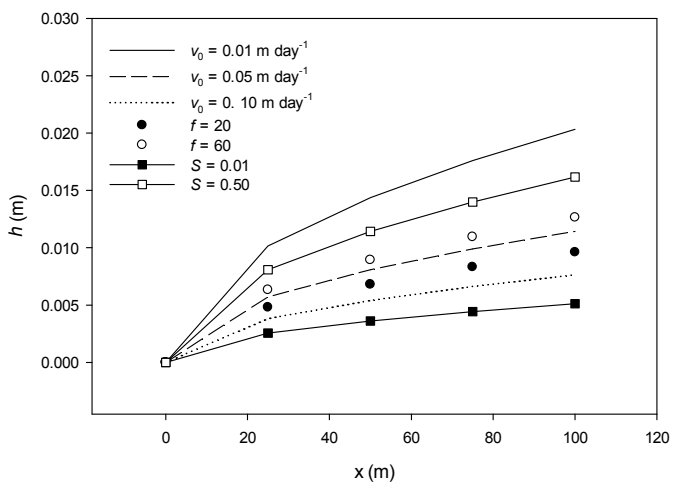

Figure 3. The effect of slope $\left(S_{0}\right)$, resistance $(f)$ and runoff rate $\left(v_{0}\right)$ on head $(h)$. The values of the properties used the medium values in Table 3 unless otherwise stated in the legend.

However, because of the relaxation in head and hence flux seen after the change at the end of the quarter (Figure 2) there is no change in runoff at the end of the slope except when the change in vegetation occurs in the last quarter of the slope sequence (Figure 4). The effect of slope, $S_{0}$, on change in runoff $(\mathrm{m}), \Delta R o$, was small compared with the effect roughness, $f$, or runoff rate, $v_{0}$ (Figure 4). This suggests that vegetation changes can have an effect on runoff from an existing slope.

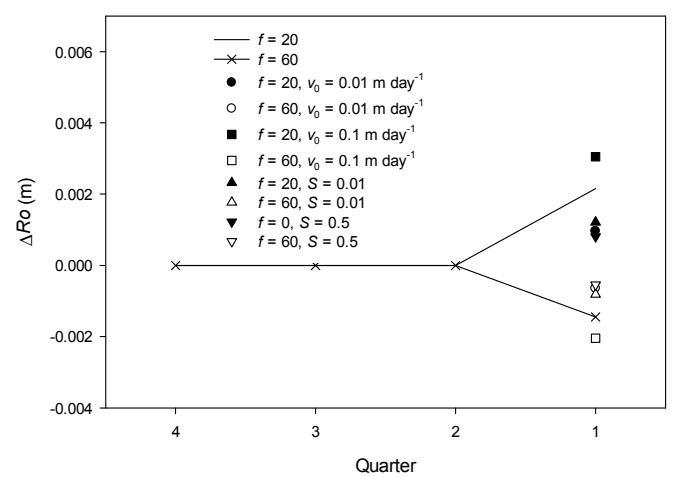

Figure 4. Change in runoff $(\Delta R o)$ over 1 day at end of slope when properties for a quarter (4 to 1) were changed from the medium properties (Table 2), and all other quarters had medium properties

The Thales simulations show significant variations in runoff for the different scenarios, with coefficients of runoff between $0-0.17$ (for Melbourne (Figure 5), 0.12-0.37 for Brisbane (Figure 6) and 0.1-0.4 for Perth (Figure 7) due to the influence of evapotranspiration and infiltration on downslope, which are not considered in eqns $1-6$.

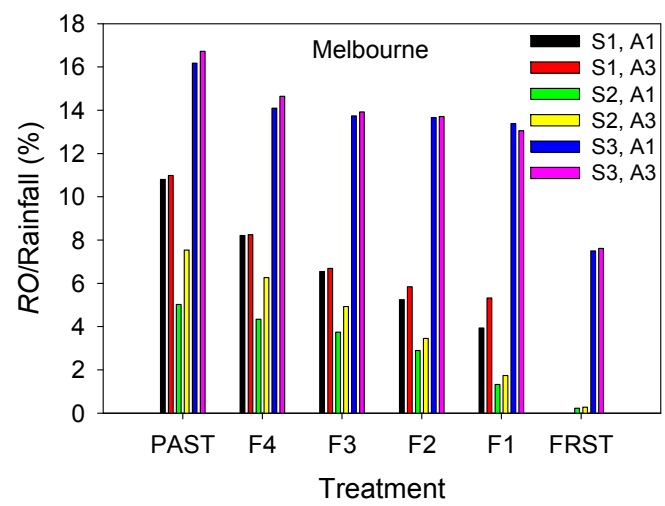

Figure 5. THALES simulation of runoff for Melbourne site for pasture (PAST), quarters 1 to 4 with trees (F1 to F4) and pasture on the rest of the slope and all trees (FRST) for different soils $(\mathrm{S} 1=$ soil \#1, S2 $=$ soil \#2 \& S3 = soil\#3) and two slopes $\left(\mathrm{A} 1=10^{\circ} \& \mathrm{~A} 2=30^{\circ}\right)$.

The soil type considered has a large effect on the proportion of runoff generated at all three locations, with the highest runoff generated for the clay profile (Figure 1, soil \#3) and the lowest generated by the soil \#2 (sandy loam over clay loam). In this profile, the sandy loam layer promotes infiltration which is subsequently lost as evapotranspiration. In the soil \#1 (all layers 
sandy loam), water can infiltrate to deeper layers reducing evapotranspiration and increasing subsurface runoff.

For Melbourne the runoff is generally from subsurface runoff for soil \#1 and \#2. For Brisbane and Perth both surface and sub-surface runoff contribute to runoff with sandy loam (soil \#1) but surface runoff is more dominant with soil \#2. With clay soil (soil \#3) runoff is predominantly from surface runoff at all three locations.

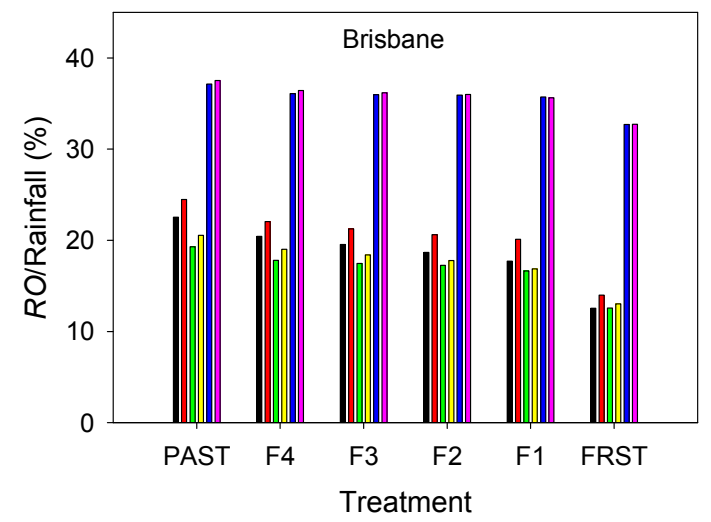

Figure 6. THALES simulation of runoff for Brisbane site nomenclature for the $\mathrm{x}$ axis and the legend is the same as figure 6.

The position of the trees on the hillslope by comparison has a smaller effect on the proportion of runoff, but the closer the tree section is to the bottom of the slope, the greater is the reduction in runoff, confirming the analytical results. This reduction is caused by capture of subsurface runoff from the upslope sections and subsequent evapotraspiration in the forest section.

The THALES modelling again indicates that the two slopes tested do no greatly influence the amount of runoff generated except for two scenarios; soil\#2 in Melbourne and soil\#1 in Perth. This is in contrast to the analytical model which suggests that slope will have a large effect on the head during runoff and hence flow (eqn (2)).

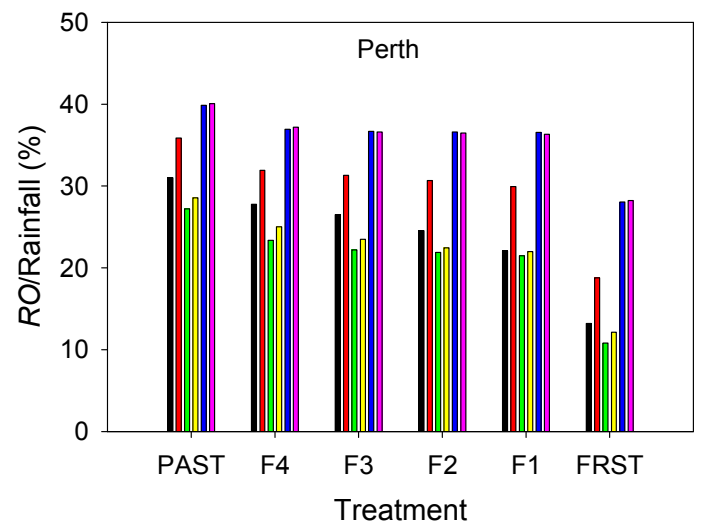

Figure 7. THALES simulation of runoff for Perth site nomenclature for the $\mathrm{x}$ axis is the same as figure 6.

\section{CONCLUSIONS AND RECOMMENDATIONS}

The results here show that the position of where trees are planted in the catchment can have an effect on the amount of runoff generated and transmitted to the end of a slope. A piecewise extension of Wooding's (1965) kinematic wave analytical solution is shown to give similar results to a numerical solution. The analytical model overestimates the head (depth of water on the soil surface) compared to the numerical model as some of the terms in eqn (1) are neglected. However, the difference in head when the roughness of a quarter section of slope was abruptly changed was similar for both models. The numerical model cannot compute the full range of possible slope lengths, runoff rate and slope angle with abrupt roughness changes as the model computations become unstable. The analytical model by comparison can be used for a wide range of values and is computationally efficient.

The analytical model shows that if vegetation (resistance to flow) is changed for a proportion of the slope the amount of runoff will be changed, but only when this change in roughness occurs at the bottom of the slope adjacent to the outlet. The analytical model suggests that water depth on the surface and hence runoff is least effected by roughness and hence vegetation change. The model suggests that runoff is more sensitive to runoff rate (rainfall minus infiltration) and slope.

The THALES catchment model show some similar results to the analytical model with the lowest quarter of the slope showing the greatest change in runoff if planted to trees, but since evapotranspiration was now taken into account it showed that planting of trees anywhere on the slope will reduce the total amount of runoff generated. These simulations indicated that the soil type can change the amount of runoff generated more that the vegetation type and texture contrast soils can produce significant sub-surface runoff. For such soils in rainfall limited climates like Melbourne this water can be captured at the end of the slope and evapotranspired by trees reducing the total runoff (Figure 6). In climates like Perth and Brisbane this did not happen to the same extent.

These results indicate that planting some of the catchment to trees is likely to change the amount of runoff generated from the catchment. However, apart from when they are plant at the bottom of the slope the 
Cook et al., Does where you plant trees make a difference in hydrological response?

position of the trees has only a small or no effect on the change in the runoff amount. The effect of slopes and the soil were also shown to have a greater affect on the amount of runoff generated than the position of the trees on the slope.

The results also show that the simple extension of Woodings (1965) runoff model can be used to assess the effects of slope, runoff rate and surface roughness on runoff and as a quick tool for assessing likely effects this could be a useful model.

\section{ACKNOWLEDGMENTS}

The eWater CRC is thanked for its funding of this research. Dr John Knight is thanked for his MatLab code to solve equation (6).

\section{REFERENCES}

Brooks, R.H., and A.T Corey (1964). Hydraulic properties of porous media. Fort Collins Colorado State University.

Carsel, R.F., and R.S. Parish (1988). Developing joint probability distributions of soil water retention characteristics. Water Resources Research, 24: 755-769.

Ellis, T.W., S. Legueddis, P.B. Hairsine, and D.J. Tongway (2006). Capture of overland flow by a tree belt on a pastured hillslope in south-eastern Australia., Australian Journal of Soil Research, 44, 117-125.

Grayson, R.B., G. Blöschl, and I.D. Moore (1995). Distributed parameter hydrologic modelling using vector elevation data: THALES and TAPES-C. Computer models of watershed hydrology. V. P. Singh. Highlands Ranch, Colorado, Water Resources Pub: 669-695.

Hairer, E., and G.Wanner (1991). Solving Ordinary Differential Equations II, Stiff and DifferentialAlgebraic Problems. Springer-Verlag, Berlin.

Henderson, F.M., and R.A. Wooding (1964), Overland flow and groundwater flow from a steady rainfall of finite duration, Journal of Geophysical Research, 69, 1531-1540.

Horton, R.E. (1936). Hydrologic interactions of water and soils. Soil Sci. Soc. Am. Proc., 1, 401-429.

Horton, R.E. (1940). An approach toward a physical understanding of infiltration capacity. Soil Sci. Soc. Am. Proc., 5, 399-417.

Moore, I. D., and G. R. Foster (1990), Hydraulics and overland flow pp. 215-254, Process Studies in Hillslope Hydrology, edited by M. G. Anderson and T. P. Burt, Wiley.

Neumann, L., A. Western, and R. Argent (2007). To Split or Lump? Influence of Spatial Respresentation in Flow and Water Quality Response Simulation. Proceedings of the International Congress on Modelling and Simulation, The Modelling and Simulation Society of Australia and New Zealand,Canberra, Australia: 2368-2374.

Neumann, L.N., A.W. Western, and R.M. Argent (2010). The sensitivity of simulated flow and water quality response to spatial heterogeneity on a hillslope in the Tarrawarra catchment, Australia. Hydrological Processes, 24 (1), 76-86.

The MathWorks Inc. (2004). MatLab Version 7 (release 14). www.mathworks.com.

Ticehurst, J.L., H.P. Cresswell, N.J. McKenzie, and M.R. Glover (2007), Interpreting soil and topographic properties to conceptualise hillslope hydrology, Geoderma, 137, 279-292.

Tarboton, D.G. (1997). A New Method for the Determination of Flow Directions and Upslope Areas in Grid Digital Elevation Models. Water Resources Research 33(2), 309-319.

Western, A.W., and R.B. Grayson (2000). Soil moisture and runoff processes at Tarrawarra. pp 209-246. Spatial patterns in catchment hydrology - Observations and modelling. R.B. Grayson, and G. Blöschl (Eds), Cambridge University Press.

Wooding, R.A. (1965), A hydraulic model for the catchment-stream problem., Journal of Hydrology, 3 , 254-267.

Zhao, F.F., L. Zhang, Z.X. Xu, and D.F. Scott (2010), Evaluation of methods for estimating the effects of vegetation change and climate variability on streamflow, Water Resources Research, 46, W03505. 